\title{
Business Network Dynamics and Diffusion of Innovation*
}

\author{
Alison Rieple ${ }^{* *}$, Marco Pironti $^{* * *}$, Paola Pisano ${ }^{* * * *}$
}

\begin{abstract}
In global markets, organizations can use 3-D printing technology to decrease the uncertainty brought by technological innovation. Through a qualitative analysis of seven case studies, the authors have identified a new business network type - defined as beta-network - characterized by a flat horizontal shape structured with a multitude of actors and weak ties. In the short term the beta-network co-exists with the incumbent network defined by a more vertical structure, fewer actors and stronger ties, while in the long term they can co-evolve in an emerging integrated network.
\end{abstract}

Keywords: Business Network; Global Markets; Innovation; Diffusion of Innovation; 3-D Printing

\section{Global Markets, Innovation and 3-D Printing Diffusion}

Several developments are changing the dominant paradigm of the XX century, or rather, mass production, vertical integrated company organizations and organization management point out new important trends for the diffusion of 3-D printing technology.

Mass production was an important goal not only for the organization but also for the satisfaction of customers' needs. Products, which were once only available to a small group of costumers, became accessible to everybody and everywhere thanks to a more capillary logistics and a more captive advertising. In fact, on the one hand, the costumers were able to buy the product they needed thanks to the logistics process, on the other, the information about the existence of the product and its characteristics induced them to desire it and consequentially buy it. Moreover, in mass production even if the costumer preferred specially tailored products, standard production was so much less expensive to produce that it overwhelmed more customized alternatives in the marketplace. So the producer

\footnotetext{
* The Authors: P. Pisano, $\S \S 3,4$.

** Professor of Strategic Management, Westminster University (a.rieple@ westminster.ac.uk)

*** Associate Professor of Management, University of Turin (pironti@ di.unito.it)

**** Assistant Professor of Management and Innovation, University of Turin (pisano@ di.unito.it)
} 
had little incentive to reinterpret the world of the costumer until the advancement in information technology and the technique of flexible manufacturing reduced the cost of product variety, moving the economy progressively away from the mass production model. This trend, reinforced by globalization and by the premium on the interpretive process that link product designers to customers on one side and designers to the production process on the other, has grown correspondently.

The past century was the stage of another important change in the manufacturing organization: going from a traditional vertically integrated firm with its clean functional divisions and clear lines of authority to a flattening of the hierarchy, decentralized decision making, and pumped up cross functional teams and network organizations. The goal was to create nimble organizations, capable of responding quickly and efficiently to rapidly changing market conditions. The manufacturing organization started to open its business model and set objectives linked with more efficiency and creativity at the same time, able to perceive and interpret the industry and costumers' change. Furthermore, the increasing cost and complexity of $\mathrm{R} \& \mathrm{D}$, the shortening of technology life cycles, the improvement of ICT technology, innovation and consequentially the increase of competition and uncertainty inside the industry push the organization to embrace coordination and integration into a value network management linking with suppliers and customers and including the identification of potential complementors and competitors.

The last important trend - as Gary Hamel underlined (2007) - is moving innovation creation from products, services or process fields to innovation management creation or, rather, a new way to link organizations - made of activities, processes, business units and team- with suppliers, partners and important clients. This new organization management is found in different businesses: InnoCentive, an Eli Lilly spin-off, manages a platform where organizations can post their technical issues that need solving on a scientist community, which will explain the unsolved problems by using the internal R\&D of the pharmaceutical organizations; Fold.it, a revolutionary new computer game enabling everyone to contribute to important scientific research; Quirky, a new venture created around the potentials of 3-D printing, based on the development of ideas and concepts suggested by users/designers which are then promoted by ecommerce channels or more traditional distribution networks, etc.

The opening of organization boundaries and the new management innovation have an important impact on 3-D printing diffusion. In the next paragraphs, using a theoretical framework on network creation and evolution, we will define three hypothesis tested in practical case analysis.

\section{Innovation Uncertainty and Network Creation}

Radical innovation technology is a complex and unpredictable event that involves a multitude of processes and interactions imperfectly understood by the organization. As a consequence, firms are not able to fully explain and accurately predict the performance of either their innovation or that of other firms. In fact, business firms are rarely capable of defining the full array of possible uses that may emerge from their innovations, especially radical ones. The recent experience of the inaccurate forecast concerning the potential market among different 
generations of mobile phones and the various functions associated with them (the unexpected success of text messaging, for instance) is equally instructive. Corporate managers face several difficulties when deciding whether to adopt or not a new innovation which has some elements of conventional investment activities but for which severe uncertainty means that continuous feedback from other adopters, such as the market and past experience, is essential. The organization's activities to reduce uncertainty will influence the selection of resources and the management of all the information regarding innovation. If innovation is perceived as attractive by the organization, the access to the technical and/or commercial resources it lacks (Ahuja 2000) as well as gaining access to skill and knowledge, particularly when time is of essence (Teece 1986; Baum et al. 2000), will drive the organization to be structured with networks.

Relationships enable actors to gain access to a variety of different resources held by other agents, lowering the information asymmetry and providing emotional support for entrepreneurial risk-taking, and this in turn is thought to enhance persistence to adopt the innovation selected (Hoang, Antoncic 2003). The literature on network formation and networking activity, therefore, clearly demonstrates that whilst firms collaborate in networks for many different reasons, the most common reason to create a new network is to gain access to new or complementary competencies and resources related to the innovation.

The fact that environmental uncertainty increases the organization's inability to assess the external environment (Powell et al. 1996) will push the firms to quickly find their organizational structure in order to manage their innovation and, consequently, their uncertainty. From this theory we are able to sustain the first hypothesis:

Hypothesis 1: The uncertainty, brought by innovation diffusion, drive organizations to structure network relationships and find distinctive resources to support their technological innovation approach.

As Galbraith (1977) proposed and research findings sustained, the uncertainty increases communication (Van de Ven et al. 1976; Katz, Thusman 1979), and consequently alliance activities. For what concern the type of relation, while strength tie or local link -are links where the new partners are found through actors' existing network (ego network) or is already known to other partners, weak link (or distant link) implies that new linkages are created with partners whom are not known to the existing partners of an actor. The local ties are drivers that reinforce the firm's social capital, decrease the risk hidden in the new partner formation process (Powell 1990; Cowan et al. 2004) and compose dense cliques of actors. Granovetter (1985) sorted out a differentiation between local ties in a dense cliques (strong tie) and distant ties that bridge these cliques (weak ties). He showed the importance of weak links to provide access to new source of information and favourable strategy negotiation position which improve the firm's position in the network and in the industry.

Basically firms are faced with the increase of uncertainty when forming linkages with other organizations that can provide them with critical resources necessary to compete in the new environment as Pfeffer and Salancik (1978) explained in their seminal work on the resource dependence theory. This way the organization will 
reduce risks caused by unpredictable future evolution through risk sharing alliances, improve its new resource source domain (Kogut 1991; Zucchella 2007) and preserve its flexibility by means of alliances.

When innovation starts to circulate into the network, the growth of uncertainty perceived by the actors will increase alliance activities with those who might reduce their uncertainty for themselves as well as for others (Hickson et al. 1971; Pfeffer 1981; Thusman, Romanelli 1983), or, rather, early adopters.

Early adopters will decrease the uncertainty on innovation by improving their knowledge, skill and capability: this process will increase their identification as experts by other members of the network (Burkhardt, Bass 1990) and will reduce the uncertainty for those members who will link with them. Contextually with the increase of the power, early adopters swap to a more central position inside the network assuming the role of central actors inside the network. Network centrality brings a better exploitation of new opportunities, influencing innovation diffusion, attracting via more new partners, via pool acquiring more resources to enhance innovation development (Soh 2010). As technology innovation is first introduced, their ability to reduce others' uncertainty is expected to be highly non substitutable, since only a few individuals (the early adopters) will be adept at working with the new system (Burkhardt, Bass 1990). In a positive inner-cycle the early adopter centrality will increase their power inside the network (Krackhardt 1990) and their reputation (Galaskiewicz 1979) becoming a strategic hub of relevant information and resource (Madhavan et al. 1998) and a significant partner to be linked with. Early adopters that realize the value of centrality may constantly be attempting to improve their centrality by connecting with more and more central partners and abandon the relationship with partners who are perceived as being less valuable, reducing the latter's centrality. From the previous theory, we are able to define our second hypothesis:

Hypothesis 2: As uncertainty increases, organizations join with a high number of new actors to explore new sources of information, skill and knowledge.

As innovation technology starts to circulate into the industry, network researchers have investigated that the increasing uncertainty reinforces previous links with existing partners (Granovetter 1982; Krackhardt 1992). In this case, firms react to their uncertainty by strengthening their ties, since strong ties are likely to be great assistance in times of change and uncertainty. The reinforcement of existing relationships facilitate the adaptation to the environment (Uzzi 1997) by improving information flow (Grannovetter 1985) and problem solving arrangements, and raise barriers for newcomers. The reinforcement of existing relationships can bring the organization to an overembeddedness where the network closes up to external information and starts having access to only redundant information leading to the stifling of innovation (Uzzi, 1997). Moreover, in the process of strong ties, new partners are found through an existing network of actors who are already known to other partners 'in the neighbourhood'. The overall network structure resulting from local link formation is a network made of dense 'cliques' of actors, which indicates that they are highly connected with each other. From the latter assertions we are able to define the final hypothesis: 
Hypothesis 3: As uncertainty increases, organizations reinforce links with previous partners or create new links with the partners of partners.

\section{From Technology to Creativity: 3-D Printing Accelerator Effect}

The reference industry of 3-D printing is difficult to define for three main reasons. First of all globalization has been blurring the traditional sector boundaries throughout much of the economy: a striking example is the interpenetration of telecommunications, information, technology, office equipment and photography (Lester, Piore 2006); second, the field of 3-D printing technology application regarding the final products includes different industries (from art to design, from fashion to photography); finally 3-D printing is used to produce components that would be costly or complex to manufacture in high technology intensity manufacturing industry (such as Aircraft and spacecraft, medical precision and optical instruments) as well as in medium -high technology intensity manufacturing industry (such as Electrical machinery and apparatus, motor vehicles, trailers and semi-trailers) as well as in low technology intensity manufacturing (such as food, textile, etc.).

The previous reasons move 3-D printing industry definition toward two main characteristics: creativity and technology.

$\square$ The UK Government's Department of Culture, Media and Sport
(DCMS) defines creative industries as: 'those industries which have
their origin in individual creativity, skill and talent and which have a
potential for wealth and job creation through the generation and
exploitation of intellectual property.' (DCMS 2001, p. 04).

The current DCMS definition recognizes twelve creative sectors, down from fourteen in their 2001 document. They are: Advertising, Architecture, Arts and antique markets, Crafts, Design, Designer Fashion; Film, video and photography; software, computer games and electronic publishing; Music and the visual and performing arts; Publishing; Television; Radio (DCMS, 2006). To this list Howkins would add toys and games, and also include the much broader area of research and development in science and technology (Howkins 2001). It has also been argued that gastronomy should be included. To conclude we decide to unite the different sectors where the 3-D printing is using through the definition of creative industries with different level of technology intensity.

3-D printing is among a spectrum of technologies being developed as a way to make it easier and more cost efficient to create parts and products in a 'personalized' way. The running of a 3-D printer starts from a software technique aimed at helping designers to create shapes of parts in three dimensions on computer screens and then transfer the instructions for making them to production machines. Such software is being used to make products on this basis in a range of industries from aerospace engines to jewellery. Laser scanning systems - made by companies such as the US's Faro Technologies - can be used to measure the dimensions of items that need to be replicated or modified. Such items could be 
anything from products or parts made by competitors - in so-called 'reverse engineering' - to parts of the human body. The information can then be converted into computer codes and sent to a production machine for turning into a solid object.

The new technology is changing many aspects of the manufacturing industry:

- the relationships between designers and production players. As Abe Reichental (probably the biggest leader in the sector) a 55-year-old Israeli-American, who is chief executive of 3-D Systems, a US company that together with Stratasys are the world's two biggest producers of 3-D printing machines, says that technology can contribute to the 'democratisation of manufacturing' by lowering the barriers between design and production. '3-D printing can provide the garage entrepreneur with the same productive capabilities as those of a large corporation' he says. The designer will have the chance to do not only the scratch but also the prototype of the product or, better, the final product. This change will allow the designer to acquire a part of the value chain belonging to the manufacturing organization.

- the personalization of the product. A key attribute is that the technology makes it possible to produce 'one-off' or highly personalised parts more easily than other manufacturing methods. This advantage will have an impact on the reduction of the relevance of inventory risk and management connected to the opportunity to print on demand the desired artifacts;

- the shortening of cycle time;

$\square$ Jeff Immelt, chief executive of General Electric1, points out the biggest impact of technology on the 'shortening cycle times' between designing products and making them. This could help manufacturers in the developed world to compensate for their higher wage costs when compared with those in more emerging economies such as China.

$\square$ Joe Hogan, chief executive of $A B B$, the Swiss-Swedish engineering group, says: '3-D printing means it's possible to go from concept to reality (in making one-off parts) in just a few hours. That's a big help when you are trying to be quicker and more reactive';

- the creation of a new opportunity;

$\square$ Scott Crump, chief executive of Stratasys, sees 3-D printing as 'part of a spectrum' of manufacturing technologies that are creating new opportunities. These include novel ways to produce the advanced software required to define shapes of products, together with new versions of more conventional cutting tools. As well as selling 3-D printing machines, Stratasys also operates factories, including the one in Minneapolis, that use this technology to make parts for customers. It recently announced a merger with Objet, an Israeli maker of 3-D printing systems, to create a larger group that will this year have comparable sales to 3-D Systems- where the figure is expected to be about 340 M\$.' 
- the decrease in production cost.

$\square$ Hans Langer, chief executive of Eos, a Munich-based company making 3-D printers, highlights the potentiality of 3-D printing '...make items that are lighter, use materials more economically and behave differently to products made today. By reducing materials and waste when making single product units 3-D printing could lead to a completely new way to approach manufacturing'.

The 3-D printing is currently used in three different fields: rapid prototyping, specific niche and final products.

Rapid prototyping was the early, and still the biggest business case for 3-D printing. In plenty of industries from architecture to aerospace, the drawing board and computer screen only takes you so far. You need to build tangible prototypes to move forward. That used to be a big expense, and more importantly, a huge time-suck: there's no reason a designer should have to wait days for someone to make a prototype until they can move forward. With a 3-D printer, designers can have a rough prototype quickly and be much more productive.

3-D printing is already being used for finished products, but still in specific niches. Some industrial components that would be costly or complex to manufacture are already being 3-D-printed. One exciting area with huge potential is prosthetics, where 3-D printers allow highly customized prosthetics to be made.

Whilst most 3-D printers are currently used for prototyping and in pre-production mould making processes, the use of 3-D printing to manufacture end-use parts is also occurring now. This manufacturing process is becoming known as direct digital manufacturing (DDM). As Fortus explains, low-volume manufacturing DDM is more cost-effective and simpler than having to pay and wait for machining or tooling, with on-the-fly design changes and just-in-time inventory being possible. For example their customer Klock Werks Kustom Cycles has built oneof-a-kind motorcycles using a Fortus 3-D printer to directly digitally manufacture some of the required custom parts.

Another company using 3-D printing to create final products is Freedom of Creation (and which was recently acquired by 3-D Systems). Their range of incredible, designer 3-D printed products includes lighting, furniture, trays, bags and jewellery. Many believe that 3-D printers have a great future in the creation of fashion items as some artists are now also using DDM to create their masterpieces.

The spread of novel 3-D printing technologies are having a great impact on organizational and business models in the sectors where it is used. By providing the opportunity to produce personalized finite and ready to sell products in smaller quantities, 3-D printing technology is both creating new business opportunities for incumbent and increasing the potential for new entrants who can leverage external creative communities

\section{Methodology and Empirical Evidence}

The methodology adopted in our study uses multiple sources and an iteractive process where the authors compared theory and data (Eisenhardt 1989). The first 
task was to understand the scope and type of the uses of 3-D printing technology world-wide, in order to understand its functionality and applications, along with associated production technologies. Thus we carried out:

- an analysis of 50 articles from international, technical and economics literatures (Business Week; Wired; the Economist and the Financial Times), that covered 3-D printing from April 2012 to November 2012; this reading enabled us, to identify our sample of practice cases;

- an analysis of different blogs on the topic of 3-D printing comprising 405 posts: this enabled us to identify emerging views on the potentials offered by this technology, on bloggers' own experience of using and interacting with the technology, and on the main companies reported as being users of 3-D printing technology.

Our sample, in line with the theoretical sampling criteria for case studies (Eisenhardt 1989; Pettigrew 1990), comprises different cases which have distinctively different approaches to their use of 3-D printing technology.

- Materialize, a company specialized in prototyping services which created, with 3-D printing, I-Materialize, a digital connection platform between creative communities and users;

- Quirky, a new venture created around the potentials of 3-D printing, based on the development of ideas and concepts suggested by users/designers which are then promoted by means of e-commerce or more traditional distribution networks;

- Fab-Lab, a global network of design shops that have 3-D technology printers, which works with small businesses, users and craftsmen in the production and sales of their products.

- Thingiverse is a place for users to share their digital designs with the world. It is a community of people who create and share designs freely, so that all can benefit from them.

- Shapeways, is an innovative New York company at the forefront of bringing the power of 3-D printing to everyday consumers - allowing anyone to create, buy and sell unique and customized products.

- Luxottica: With net sales reaching Euro 6.2 billion in 2011, over 65,000 employees and a strong global presence, Luxottica is a leader in the design, manufacture, distribution and sales of premium, luxury and sports eyewear.

- Gardena: located in Ulm (Germany) is a manufacturer of gardening tools with approximately 2,800 employees worldwide (including 1,600 in Germany), and an annual turnover of 393 million euros. Gardena is a market leader in Europe.

All practice cases in the previous list are using the new technology increasing relationship as we have underlined in the first proposition. While the previous five cases have developed their business around 3-D printing technology based on the concept of community where the knowledge and the skill to develop the projects come from external sources fragmented in the community of users, designers, technicians, the second category of cases have improved their capabilities of managing and exploring 3-D printing innovation by joining with external suppliers (like Gardena with their 3-D system) or improving their internal ability (like Luxottica). 
All platforms let users upload and share digital designs with others and, in the case of Shapeways or Fab Lab, leverage printing centres on demand to produce the products that users have ordered and have them delivered by mail only days later.

The process of digital design sharing is led by a proportionately large number of designers both inside and outside the firm cooperating with platforms toward weak and, often, distant links. For Example, Quirky has 8 designers on staff out of a total of 40 people in the firm, plus a larger, but indeterminate, number of external designers brought in as necessary.

Of course the users can decide to create by themselves the digital design useful to print or download the product (as it happens in Thingiverse) modifying it if required.

The idea submitted in Quirky receives a double evaluation from both community and Quirky's staff members. Fab-lab lends 3-D printers and linked technological devices to those inventors and/or designers who can prove their ability, or who have been educated by the Fab Lab Academy to use these technologies properly.

The intrinsic characteristics of 3-D printing technology also enable the production of different categories of products, in limited quantities and without any technological complementarities between them. In all of our sample organizations, a heterogeneous range of goods is produced, including fashion accessories, jewels, toys, shoes, musical instruments, lamps, and interior design products. In fact, the major problems connected with this technology concern the ability to use different raw materials and the ability therefore to source and sell products with diverse components to diverse customers.

Skills in managing mainly external creative resources connected with crowdsourcing or externally sourcing design know-how, combined with expertise in the use of 3-D printers, form the two main types of capabilities in both conception-conceptualization and production.

Quirky, I-Materialize, and Shapeway, who have been excited about the idea of a creative marketplace community, have developed on-line shops that give users the chance to buy products generated by independent users/designers. Alongside this, Quirky, in line with the logic of pushing a distribution strategy, partners with a network of retailers that sell products produced on their own platform. Firms specializing in organized distribution, such as Safeway, Target, Barnes \& Noble, Amazon, and Toys ' $R$ ' Us, are a few of the companies where you can buy products made by Quirky. Enterprises like Fab-lab have a world-wide distribution network with over 50 laboratories open to designers, production self learners, and consumers driven by the desire to personalize small products such as accessories, musical instruments or toys. Fab-lab's model introduces a further innovative element, their territorial presence, which, being often highly integrated with the local social milieu, encourages the direct involvement of the final client, bypassing normal distribution channels. As a result the client becomes not only the buyer but also an important tester of product effectiveness or of the idea conceived in the labs. through this type of client management the organization develops a tough market driven strategy to compete in the open market (Brondoni 2009). The first five practice cases give consistency to the second hypothesis where the organization partners with high number of new actors, not necessary closed to the central actors and not linked with durable and strong ties with the project actor. 
Luxottica and Garden have approached the new technology in a different way. With the vertical integration of the production system, Luxottica has created a virtuous circle: the complete control of production allows for research into new technologies, which in turn results in improved efficiency and an increase in revenues; the company grows and this stimulates investment and research. This vertical integration strategy decided by Del Vecchio is a key element for Luxottica, as it has allowed the Agordo-based company to maintain a cost leadership position in the sector, associating it with a high quality product. The vertical integration process has entailed major investments, on the one hand in order to extend production capacity and, on the other, to renew production technology, but always in the fundamental, total respect of high product quality. However, Gardena has decided to improve the quality of production, making the supply chain more efficient with their 3-D system. Basically the relationship among suppliers, clients and partners has not changed as the new partner is added to the current network as a service supplier. Of course the new partner was selected considering its capability and expertise on the new technology. In fact 3-D Systems is a leading, global provider of 3-D content-to-print solutions including personal, professional and production 3-D printers, integrated print materials and on-demand custom parts services for professionals and consumers alike. This last findings are in line with the third hypothesis.

The analysis of these practice cases have underlined the emerging of a new network formed by a multitude of actors linked with a platform where each partner collaborates in the 3-D printing manufacturing, sharing the entire business process, from the idea to its accomplishment. Thanks the high net of links the final product -in the form of electronic copy- can circulate until it reaches the lab closer to the costumer. This new network seems to have the features of a- beta-network or, rather, the preliminary or tested phase of a network. The beta-network coexists with the current manufacturing-based network, without trying to replace the latter in the short term. In this emerging relationship system, the use of innovation technology is stressed by different actors and into different projects and industries. If competitive dynamics show positive and successful effects, in the long term the two different networks can co-evolve, generating a new arena where incumbents and new comers change their role and adopt different and innovative business models.

\section{Emerging Issues and Conclusions}

The development of 3-D printing in modern industrial and manufacturing economies is promoting new competitive mechanisms based on different network structures. In particular, it seems that a new competitive arena is emerging in services connected with design and creativity, rather than having a pre-existent radical change in the design and creativity professional services. In the current competitive arena, which features stable and consolidated relationships between large-scale production players, incumbent designers and design consulting firms (Capaldo 2007; Dell'Era, Verganti 2010), there is now a new scenario that features new players (including newcomer designers and small-scale producers) who base their competitive advantages on a new external networks - the beta-network - that 
leverage spreading creativity models. The proliferation of instruments and software open to design, the spread of cultures linked to 'making' and advanced selfproduction (Senneth 2008; Micelli 2011), together with the potential of the $2.0 \mathrm{web}$ and social networks, are the key factors and the background for the development of these new forms of creativity and manufacturing.

This latter scenario does not appear, at least currently, to be competing with the current scenario, which is founded on a trading relationship between incumbents (manufacturers and designers). It coexists with the previous one and focuses on providing Business to Business (BtoB) or Business to Consumer (BtoC) offer systems to markets in which content sharing and the manufacturing of products developed in a shared manner acquire their own value, overcoming the classical logic of Fordist trading. In this scenario, new technologies (e.g., 3-D printing) do not have a central or leading role, but they are trend accelerators of a new and growing business model. 3-D printing technology induces both incumbent players and new entrepreneurs to develop links through a marketplace centered on community and design/manufacturing crowdsourcing. All the relationships that emerge in this new context often surpass the traditional vertical relationships between supplier, producers and distributors. Inside this expanding context, products do not have technological complementarities or branding relationships. With 3-D printers - given material limitations - companies produce lamps, shoes, accessories, or toys, without any type of category ties and complementarities. The absence of merchandise categories prompts us to reconsider, even if only partially, the traditional boundaries between companies and the players' relationships within the value chain.

As revealed in the empirical survey of selected cases, the beta-network induces companies to define a profitable product portfolio based on a wide variety of customized and low-volume products with no technological complementarities, where the process and community management prevails over brand management.

In the short term, the creation of a beta-network allows to evaluate sustainability and profitability of new business models and emerging relationship caused by the diffusion of innovation. In case of a positive and successful scenario, in the long term we expect the co-evolution with the existing manufacturing-based network, thus, a redesigning of a new competitive arena: some incumbent players will be thrown out or reshaped, other new comers will strengthen competitive advantages acquiring a central role in the new network.

Given its focus on empirical evidence from the diffusion of 3-D printing, our analysis cannot be employed to identify the specific features of a new emerging industry, but aims to present some first-hand trends in creativity industries. The propositions suggested in this paper provide cues for future research studies that aim at developing a deeper understanding of how the diffusion of innovation and these open models are affecting the creativity chain and how manufacturers engage new players and designers in their innovative processes. 


\section{Bibliography}

Ahuja Gautam (2000) Collaboration Networks, Structural Holes and Innovation: a Longitudinal Study, Administrative Science Quarterly, vol. 45, pp. 425-455. http://dx.doi.org/10.2307/2667105

Baum Joel A. C., Calabrese Tony, Silverman Brian S. (2000) Don't Go it Alone: Alliance Network Composition and Startups' Performance in Canadian Biotechnology, Strategic Management Journal, vol. 21, pp. 267-294. http://dx.doi.org/10.1002/(SICI)1097-0266(200003)21:3<267::AID-SMJ89>3.0.CO;2-8

Brondoni Silvio M. (2009) Market-Driven Management, Competitive Customer Value and Global Network, Symphonya. Emerging Issues in Management (symphonya.unimib.it), n. 1. http://dx.doi.org/10.4468/2009.1.02brondoni

Burkhardt Marlene E., Brass Daniel J. (1990) Changing Patterns or Patterns of Change - The Effects of a Change in Technology on Social Network Structure and Power, Administrative Science Quarterly, vol. 35, n. 1, pp. 104-127. http://dx.doi.org/10.2307/2393552

Capaldo Antonio (2007) Network Structure and Innovation: the Leveraging of a Dual Network as a Distinctive Relational Capability, Strategic Management Journal, vol. 28, n. 6, pp. 585-608.

http://dx.doi.org/10.1002/smj.621

Cowan Nelson, Chen Zhijian, Rouder Jeffrey N. (2004) Constant Capacity in an Immediate SerialRecall Task: a Logical Sequel to Miller (1956), Psychological Science, vol. 15, n. 9, pp. 634-640. http://dx.doi.org/10.1111/j.0956-7976.2004.00732.x

DCMS (2001) Creative Industries Mapping Document 2001, (2 ed.), Department of Culture, Media and Sport London, UK.

DCMS (2006) Creative Industries Statistical Estimates Statistical Bulletin, Department of Culture, Media and Sport, London, UK.

Dell'Era Claudio, Verganti Roberto (2010) Collaborative Strategies in Design-intensive Industries: Knowledge Diversity and Innovation, Long Range Planning,vol. 43, n. 1, pp. 123-141. http://dx.doi.org/10.1016/j.lrp.2009.10.006

Eisenhardt Kathleen M. (1989) Building Theories from Case Study Research, The Academy of Management Review, vol. 14, n. 4, pp. 532-550.

http://dx.doi.org/10.5465/AMR.1989.4308385

Galaskiewicz Joseph (1979) Exchange Networks and Community Politics, Sage Publications, Beverly Hills, CA.

Galbraith Jay R. (1977) Organization Design, Reading, Addison-Wesley, MA.

Granovetter Mark (1985) Economic Action and Social Structure: the Problem of Embeddedness, American Journal of Sociology, vol. 91, n. 3, pp. 481-510. http://dx.doi.org/10.1086/228311

Granovetter Mark (1982) The Strength of Weak Ties: a Network Theory Revisited in Marsden P. V., Lin N. (Eds.), Social Structure and Network Analysis, Sage, Beverly Hills, CA, 1982, pp. 105130.

Hamel Gary (2007) The Future of Management, HBS Press.

Hickson David J., Hinning Chirstopher R., Lee Charles A., Schnech Rodney E., Pennings Johannes M. (1971) A Strategic Contingency Theory of Intraorganizational Power, Administrative Science Quarterly, vol. 16. http://dx.doi.org/10.2307/2391831

Hoang Ha, Antoncic Bostjan (2003) Network-Based Research in Entrepreneurship: a Critical Review, Journal of Business Venturing, Elsevier, vol. 18, n. 2, pp. 165-187. http://dx.doi.org/10.1016/S0883-9026(02)00081-2

Howkins John, The Creative Economy: how People Make Money from Ideas, Penguin, 2001.

Katz Ralph, Tushman Michael (1979) Communication Patterns, Project Performance, and Task Characteristics: an Empirical Evaluation and Integration in an R\&D Setting, Management Science, vol. 23, pp. 139-162. 
http://dx.doi.org/10.1016/0030-5073(79)90053-9

Kogut Bruce (1991) Ventures and the Option to Expand and Acquire, Management Science, vol. 37, n. 1, pp. 19-33.

http://dx.doi.org/10.1287/mnsc.37.1.19

Krackhardt David (1990) Assessing the Political Landscape: Structure, Cognition, and Power in Organizations, Administrative Science Quarterly, vol. 35, pp. 342-369.

http://dx.doi.org/10.2307/2393394

Krackhardt David (1992) The Strength of Strong Ties: the Importance of Philos in Organizations in Nohria N., Eccles R. C. (Eds.), Networks and Organizations: Structure, Form, and Action, Harvard University Press, Cambridge, MA, pp. 216-239.

Lester Richard K., Piore Michael J. (2006) Innovation - The Missing Dimension, Harvard University Press, Cambridge, MA.

Madhavan Ravindranath, Koka Balaji R., Prescott John E. (1998) Networks in Transition: how Industry Events (re)shape Interfirm Relationships, Strategic Management Journal, vol. 19, n. 5, pp. 439-459.

http://dx.doi.org/10.1002/(SICI)1097-0266(199805)19:5<439::AID-DIA952>3.3.CO;2-U

Micelli Stefano (2011) Futuro Artigiano, L'innovazione nelle mani degli Italiani, Marsilio.

Pettigrew Andrew M. (1990) Longitudinal Field Research on Change: Theory and Practice, Organization Science, vol. 1, n. 3, pp. 267-292.

http://dx.doi.org/10.1287/orsc.1.3.267

Pfeffer Jeffrey (1981) Power in Organizations, HarperCollins.

Pfeffer Jeffrey, Salancik Gerald R. (1978) The External Control of Organizations: a Resource Dependence Perspective, Harper \& Row, New York.

Powell Walter W., Koput Kenneth W. , Smith-Doerr Laurel (1996) Interorganizational Collaboration and the Locus of Innovation: Networks of Learning in Biotechnology, Administrative Science Quarterly, vol. 41, pp. 116-145. http://dx.doi.org/10.2307/2393988

Powell Walter W. (1990) Neither Market nor Hierarchy: Network Forms of Organization, in Staw B. M., Cummings L. L. (eds.) Research in Organizational Behavior, JAI, pp. 295-336.

Senneth Richard, The Craftsman, Yale University Press, New Haven, London, 2008.

Soh Pek-Hooi (2010) Network Patterns and Competitive Advantage before the Emergence of a Dominant Design, Strategic Management Journal, vol. 31, n. 4, pp. 438-461. http://dx.doi.org/10.1002/smj.819

Teece David J. (1986) Profiting from Technological Innovation: Implications for Integration, Collaboration, Licensing and Public Policy, Research Policy, vol. 15, pp. 285-305. http://dx.doi.org/10.1016/0048-7333(86)90027-2

Tushman Michael L., Romanelli Elaine (1983) Uncertainty, Social Location and Influence in Decision Making: a Sociometric Analysis, Management Science, vol. 29, n. 1, pp. 12-23. http://dx.doi.org/10.1287/mnsc.29.1.12

Uzzi Brian (1997) Social Structure and Competition in Interfirm Networks: the Paradox of Embeddedness, Administrative Science Quarterly, vol. 42, pp. 35-67. http://dx.doi.org/10.2307/2393808

Van de Ven Andrew H., Delbecq Andre L., Koenig Richard Jr. (1976) Determinants of Coordination Modes within Organizations, American Sociological Review, vol. 41, n. 3. http://dx.doi.org/10.2307/2094477

Zucchella Antonella (2007) Network Social Responsibility, Symphonya. Emerging Issues in Management (symphonya.unimib.it), n. 2.

http://dx.doi.org/10.4468/2007.2.07zucchella

\section{Notes}

${ }^{1} \mathrm{GE}$ is using 3-D printing to make prototype components for testing in its divisions that produce domestic appliances and aerospace engines. 